\title{
Letters
}

Website: bmj.com

Email: letters@bmj.com

\section{The "redisorganisation" of the NHS}

Is mass dysmorphophobia a better term? EDITOR-After six organisational reconfigurations in the course of 15 years as a consultant I was delighted to read that a respected unit (the Health Services Management Centre) considers that there is no research evidence for the recent change. ${ }^{1}$ But would it not be useful to study the experiences of those of us, mainly senior nurses and consultants, who have had to carry on delivering clinical services amid the routine changes of management?

For example, it takes at least two years for organisations to work out who does what, to rewrite the priorities and protocol strategies, and to settle arguments within the region/health authority/trusts as to how much money they should have even though they don't have it. Most typical is the reintroduction of arrangements that failed five years ago, under the aegis of a "robust" (or "innovative") "change facilitation." There is also no research into what happens to those people displaced by this process. Like sacked football managers they seem to mill around as management consultants or emerge as part of a new agency or a deanery add-on-quango-like organisations generating meetings and paperwork.

\section{Advice to authors}

We prefer to receive all responses electronically, sent directly to our website. Processing your letter will be delayed unless it arrives in an electronic form.

We are now posting all direct submissions to our website within 24 hours of receipt and our intention is to post all other electronic submissions there as well. All responses will be eligible for publication in the paper journal.

Responses should be under 400 words and relate to articles published in the preceding month. They should include $\leqslant 5$ references, in the Vancouver style, including one to the BMJ article to which they relate. We welcome illustrations.

Please supply each author's current appointment and full address, and a phone or fax number or email address for the corresponding author. We ask authors to declare any competing interest. Please send a stamped addressed envelope if you would like to know whether your letter has been accepted or rejected.

Letters will be edited and may be shortened.

bmj.com

letters@bmj.com
Health service management is difficult, and I sympathise with those involved in its current rearrangements. This persistent preoccupation with appearance is a form of dysmorphophobia, the near-delusional conviction of (usually) facial disfigurement that drives patients to have multiple cosmetic operations. The correct treatment, of course, is to refuse to operate and restore realistic thinking.

\section{Trevor Turner clinical director}

Division of Psychiatry, Homerton University Hospital, East London and The City NHS Mental Health NHS Trust, London E9 6SR

1 Smith J, Walshe K, Hunter DJ. The "redisorganisation" of the NHS. BMJ 200 1;323:1262-3. (1 December.)

Radical changes can be made only if the basic environment is stable

EDITOR-There is no question that much is wrong in the organisation and management of the NHS. ${ }^{1}$ The government's error is to think that it can solve the problems with structural change. A lesson I learnt from nine years on a hospital board was that management could make radical changes only if the basic environment was stable. In our case some radical developments took place in the way services were delivered, which contributed to solving problems of waiting times, responsiveness to patients needs, and quality of care. These happened with the support of clinical staff.

There is no perfect structure. Function is more important than structure. The focus should be on making the existing arrangements work. An important starting point is to learn to leave things alone.

Charles Normand professor of health economics London School of Hygiene and Tropical Medicine, London WC1E 7HT

charles.normand@lshtm.ac.uk

1 Smith J, Walshe K, Hunter DJ. The "redisorganisation" of the NHS. BMJ 2001;323:1262-3. (1 December.)

\section{Doctors must have more managerial training}

EDITOR-Dare I predict that the next crisis will be because disillusioned managers leave the NHS and general practitioners are found not to have sufficient managerial (never mind leadership) skills to undertake the agenda now placed in their lap, and so the government agenda is not delivered and the public suffers? ${ }^{1}$ This is but one scenario, and I hope I am wrong. Surely, though, one of the lessons of the events at Bristol is that without sufficient managerial (as opposed to professional) skill at the top of these large and complex organisations, professional skills alone will prove inadequate to meet the task.

Should we be surprised if some doctors and even nurses of the future disclaim responsibility for managerial failures on the grounds that they were not given sufficient managerial training and development for the roles now thrust on them by both default and design?

Annabelle Mark professor of healthcare organisation Middlesex University Business School, Hendon, London NW4 4BT

a.mark@mdx.ac.uk

1 Smith J, Walshe K, Hunter DJ. The "redisorganisation" of the NHS. BMJ 2001;323:1262-3. (1 December.)

\section{GPs' dissatisfaction with NHS plan is worse than editorial suggests}

EDitor-Smith et al quote a level of $80 \%$ dissatisfaction with the NHS plan, which I would take issue with. ${ }^{1}$ At a conference for general practitioners that I chaired the plan was discussed over three hours. The lecturer was an expert on the plan and on medical economics.

At the start of the lecture the question asked was, "Do you approve of the NHS plan?" Of the 50 general practitioners present, one approved, three abstained, and the rest disapproved. When the same question was asked at the end of the lecture, by which time the delegates presumably understood the details of the plan, all indicated that they did not approve of it. Thus this group, from all over the United Kingdom, showed 100\% dissatisfaction.

\section{Peter Barling general practitioner \\ Oswestry ST10 7HR}

vronlodge@aol.com

1 Smith J, Walshe K, Hunter DJ. The "redisorganisation" of the NHS. BMJ 2001;323:1262-3. (1 December.)

\section{Doctors working in public health have} extra worries in latest reorganisation

EDITOR-Smith et al's editorial on the disorganisation of the NHS failed to refer to one particular group on whom the current structural changes are having a profound impact: those in public health. ${ }^{1}$ In addition to the stress and low morale experienced by the other professions and managers (described by Smith), since April 2001 most NHS public health specialists in England have had to face making sense of yet further structural change.

The problem is not that public health is not relevant, for there has never been a time 
with more discussion of social and health inequalities. Within the current reorganisation, however, most public health specialists-both doctors and those from multidisciplinary backgrounds-work at one of the tiers currently being reorganised. Since last April they have not known where they will be working on 1 April 2002.

Working in public health within the NHS requires a long term view. Successful practice is based on relationships with a wide range of people, including those in the NHS, local authorities, the local community, and the voluntary sector; these relationships build up over years. This does not make the headlines in a media obsessed with waiting lists and hospitals, but nurturing it is crucial to meeting the inequalities targets in the NHS plan.

Some people in public health see this reorganisation as one too many. There is an increasing mismatch between the geographical boundaries of democratically elected civic society and the NHS at the level of primary care trusts and strategic health authorities. The relationships built up between directors of public health and their civic partners are in danger of being dismissed. No one primary care trust will now cover large cities such as Birmingham or Sheffield. This creates the risk both of confusing the public and of failing to value wisdom and skill.

There can be solutions. Primary care trusts and public health specialists can work in networks that reflect local government boundaries wherever possible. ${ }^{2}$ The new roles for the trusts and regional government offices offer opportunities for all staff working at these levels. ${ }^{3}$ The opportunity to develop a multidisciplinary profession exists. ${ }^{4}$ But if this reorganisation is not to weaken the public health function a sustained input of energy, time, and resources will be needed from the government to promote this agenda. This means not only supporting the general political philosophy of addressing poor health through economic investment but giving active support to people working in public health.

Sian Griffiths president

Faculty of Public Health Medicine, London NW1 4LB

president@fphm.org.uk

1 Smith J, Walshe K, Hunter DJ. The "redisorganisation" of the NHS. BMJ 2002;323:1262-3. (1 December.)

2 Faculty of Public Health Medicine, Public Health and Primary Care Group, Health Development Agency Consensus statement on public health networks. London: FPHM, 2001.

3 Department of Health. Shifting the balance of power: next steps. London: DoH, 2002.

4 MePhorson K, T H, S. Public health does not need to be led by doctors: for and against. BMJ 2001;322:1593-6.

\section{Effectiveness of guidelines on persistent glue ear in children}

\section{Authors' estimates of size of impact are probably excessive}

EDITOR-Mason et al have shown how the Effective Health Care bulletin on treating persistent glue ear in children was associated with a subsequent significant decline in rates of surgery for this condition. ${ }^{1}$ Their estimates of the size of the impact, however, are probably excessive. This illustrates the dangers of undertaking short time series analyses.

They compared surgical rates after publication of the bulletin with the rates in the preceding three years. They report that during the preceding years the rate rose from about 1.7 to 2.1 per 1000 children. The rise over this period, however, does not reflect the longer term trends in the surgical rate observed in children aged under 10 in the districts covered by the old Oxford and East Anglian regions: the rate peaked in the mid-1980s and then fell slowly but steadily during the following six years. ${ }^{2}$ Mason et al seem to have based their claim that the rate increased greatly during the 1980 s on a paper that covered the period only up to $1982 .^{3}$

The upturn during 1989-92 has to be seen in the context of an overall decline from 1985 to the present day. The reason for the short reversal in an otherwise steady decline is unclear. One clue is provided by the observation that the same happened for tonsillectomy rates, which, with the exception of an upturn in 1989-92, have continued their longstanding decline right up to the present day.

This paper illustrates the need, when undertaking time series analyses, to consider a sufficiently long period.

Nick Black professor of health services research nick.black@lshtm.ac.uk

Andrew Hutchings lecturer

Department of Public Health and Policy, London School of Hygiene and Tropical Medicine, London WC1E 7HT

1 Mason J, Freemantle N, Browning G. Impact of Effective Health Care bulletin on treatment of persistent glue ear in til

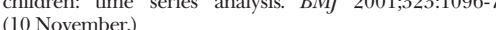

2 Black NA. Surgery for glue ear: the English epidemic wanes. J Epidemiol Community Health 1995;49:234-7.

3 Black NA. Surgery for glue ear-a modern epidemic Lancet 1984;i:835-7.

\section{Effect claimed may depend on how persistent glue ear is defined}

EDITOR-Mason et al reported a dramatic decline in procedures to insert grommets for glue ear in the population of England aged under $15 .{ }^{1}$ This prompted us to re-examine our earlier analysis of the same dataset for the same condition, included in an evaluation of the reports published by the South and West Development and Evaluation Committee. ${ }^{2}$ The committee's recommendation that glue ear should be managed by a period of watchful waiting mirrored that of the Effective Health Care bulletin studied by Mason et al. ${ }^{4}$ Unlike the result reported in the bulletin, however, we concluded that the committee's report, published two years after the bulletin, had no discernible effect.

In the same way as Mason et al did, we identified all grommet procedures from hospital episode statistics OPCS-4 surgical code D15.1 for inpatient and day case admissions. Our analysis of the data for all England shows that although the annual rate for all grommet procedures carried out in the population aged under 15 declined significantly between 1992-3 and 1997-8, as Mason et al showed, those procedures carried out specifically for persistent glue ear remained relatively constant.

Limiting the number of different ICD-9 (International Classification of Diseases ninth revision) codes in the hospital episode statistics surgical code D15.1 to those containing over 100 cases in 1992 yielded 49 different codes. In 1994 it yielded 57 different codes. We selected ICD-9 codes 381.2, 381.29 , and 381.20, and ICD-10 code H65.3 (for chronic mucoid otitis media (glue ear)) to isolate those procedures carried out on children whose reason for admission was "persistent glue ear" from those carried out for other conditions. The rate of grommet insertion fell by $21 \%$ (from $3.3 / 1000$ children aged under 15 in 1992-3 to $2.6 / 1000$ in 1997-8) for glue ear but by $35 \%$ (from $4.9 / 1000$ to $3.2 / 1000$ ) for conditions not coded specifically as glue ear.

The recommendations of the development and evaluation committee's report," like those of the Effective Health Care bulletin, ${ }^{4}$ were specific to the insertion of grommets for persistent glue ear in children aged under 15 , and the finding of a greater decline in other conditions suggests that it was not the committee's report that caused the decline. We may have been too restrictive in the codes that we applied to extract the data specific to glue ear, but the impact of the Effective Health Care bulletin on procedures for persistent glue ear would be better understood if the methods that Mason et al used to identify grommet procedures for this condition from others in the routine data were made explicit.

P Coleman research fellow, Medical Care Research Unit P.Coleman@sheffield.ac.uk

J Nicholl director, Medical Care Research Unit E Warren operational research analyst

Sheffield School for Health and Related Research, University of Sheffield, Sheffield S1 4DA

1 Mason J, Freemantle N, Browning G. Impact of Effective Health Care bulletin on treatment of persistent glue ear in children: time series analysis. BMJ 2001;323:1096-7. (10 October.)

2 Nicholl J, Coleman P, Touch S, Brennan A, Dixon S. An evaluation of the impact, quality and value of the South and West development and evaluation (DEC) reports. Final report to the NHS Executive South and West. Sheffield: Sheffield School for Health and Related Research (ScHARR), 2000.

3 Insertion of prommets for glue ear. Southampton: Wessex Insertion of grommets for glue ear. Southampton: Wessex development and evaluation (DEC) report No 26.)

4 The treatment of persistent glue ear in children. Effective The treatment of pers
Health Care 1992;No 4.

\section{Guidelines in Australia were less effective} than guidelines in England

EDitor-Mason et al report that, in the four years after the distribution of an Effective Health Care bulletin, the quarterly rate of grommet insertions fell from 2.1/1000 children under 15 in 1992 (equivalent to an annual rate of 8.4/1000) to 1.5/1000 in 1996 (as calculated from the quoted decrease of $0.044 / 1000$ per quarter). ${ }^{1}$ We adopted a similar method to examine the effect of the introduction of clinical guidelines on rates of myringotomy (with or without insertion of tympanostomy tubes) ${ }^{2}$ among children under 15 in New South Wales. 
By 1992-3 (the year before dissemination of the guidelines) the annual myringotomy rate in New South Wales had reached 8.1/1000 children under 15 . In the three years immediately after the guidelines were disseminated we too found that annual rates of the procedure fell (to 7.6/1000, 7.4/ 1000 , and $6.9 / 1000$ respectively). In the next years (1996-7, 1997-8, and 1998-9), however, rates rose again to levels similar to those in the period before the guidelines were disseminated $(7.8 / 1000,7.5 / 1000$, and $7.7 / 1000$ respectively).

Our results with regard to tonsillectomy also differed. Far from displaying an independent trend, rates of tonsillectomy moved almost in tandem with myringotomy rates, falling at the same time and then rising again to their 1992-3 level. We hypothesise that paying attention to one ear, nose, and throat procedure prompted examination of another.

The reason for such conflicting results in the two countries is unknown. If guidelines are solely responsible for the changes observed in clinicians' behaviour then perhaps the failure to sustain decreased rates in New South Wales could be due to differences in the content, presentation, or dissemination of the guideline. Given the literature on the effectiveness of guidelines on clinical practice, ${ }^{3}$ however, we would argue that other factors are likely to have contributed to the outcomes reported by Mason et al.

Marilyn I Rob PhD student, Faculty of Medicine Johanna I Westbrook associate professor of medical informatics, Centre for Health Informatics J.Westbrook@unsw.edu.au

University of New South Wales, Kensington, 2052 New South Wales, Australia

1 Mason J, Freemantle N, Browning G. Impact of Effective Health Care bulletin on treatment of persistent glue ear in children: time series analysis. BMJ 2001;323:1096-7. (10 November:

2 NSW Health Department Working Party. Guidelines on the management of paediatric middle ear disease. Med Aust 1993;159(suppl):S1-8.

3 Gross P, Greenfield S, Cretin S, Ferguson J, Grimshaw J, Grol R, et al. Optimal methods for guideline implementation: conclusions from Leeds Castle meeting. Med Care 2001;39(suppl 2):85-92

\section{Why general practitioners do not implement evidence}

\section{Evidence seems to change frequently}

EDITOR-Freeman and Sweeney's study on why general practitioners do not implement evidence seems to share the underlying assumption of so much that is written on this subject-that evidence is clear cut, and the only problem is getting practitioners to put it into practice. ${ }^{1}$ My perception of evidence, however, is that it is often slippery-at best frequently changing and at worst contradictory and confusing-and that best evidence is often not very good. Part of the problem is therefore deciding exactly what to put into practice.

The findings and interpretation of individual papers, systematic reviews, metaanalyses, and reviews of systematic reviews and meta-analyses are regularly debated in the BMJ. Anticoagulation was one of the clinical areas discussed by the participants in Freeman and Sweeney's study, but stroke prevention in atrial fibrillation is controversial. How many general practitioners who have read the papers on atrial fibrillation in the $B M J$ over the past couple of years feel confident about the conclusions to be drawn from this evidence as to which of their patients would be best treated with warfarin and which with aspirin? Clinical Evidence helps, ${ }^{2}$ but can we be sure that its authors are more objective than the combatants in the $B M J$ ?

The fickleness of evidence is inconvenient but would be easier to live with if it was more widely acknowledged in discussions of implementation.

John Temple part time lecturer

Division of General Practice, Medical School, Nottingham University, Nottingham NG7 2UH john.temple@nottingham.ac.uk

1 Freeman AC, Sweeney K. Why general practitioners do not implement evidence: qualitative study. BMJ 2001;323 1100-2. (10 October.)

2 Barton S, ed. Clinical evidence. Issue 5. London: BM Publishing Group, 2001.

Learning environments must be created that capitalise on teams' wealth of knowledge

EDITOR-Freeman and Sweeney's paper on why general practitioners do not implement evidence highlights the importance of good knowledge management for primary care and the weakness of relying solely on the dissemination of evidence based medicine. Evidence based medicine is an explicit and highly formalised form of knowledge made available though journals, websites, and lectures. Added authority is given when it is made part of national targets or incentive schemes.

By way of contrast the commercial knowledge management literature, while acknowledging the need for explicit knowledge, places enormous value on tacit knowledge. ${ }^{2}$ Tacit knowledge includes intuition and problem solving ability that is gained through experience and interaction with people. Externalisation of this tacit knowledge, so that organisations and individuals can learn from it, is seen as critical to commercial success. Forums for learner centred approaches to knowledge management, where this tacit knowledge is shared, are small groups, workshops, and one to one learning situations.

Freeman and Sweeney's paper shows how, through evidence based medicine, primary care is provided with a language to describe formalised explicit knowledge. What seems to be lacking is a language for valuing and externalising the tacit knowledge possessed by primary care professionals. ${ }^{3} \quad$ The paper lends support to the argument that primary care organisations need to have knowledge management strategies that aren't simply about delivering explicit formalised knowledge. This is not to decry evidence based medicine but to argue that other knowledge management strategies are needed as well.
It is all too easy for front line medical services such as general practice to be seen as routine patient management problems ${ }^{4}$ that can be solved by the dissemination of evidence based medicine and information centred knowledge. The assumption is that all general practice needs is access to the right decision support; evidence based medicine will then be implemented.

Wyatt says that strategies to use tacit knowledge should not occur "at the expense of distracting clinicians, policy makers and funders from the key task of making agreed explicit knowledge readily available in suitable forms." ${ }^{4}$ Freeman and Sweeney's paper provides a refreshing challenge to this by highlighting the social complexity of implementing evidence based medicine. The knowledge management literature suggests that a learner centred approach, exploiting tacit knowledge, can address some of these issues.

Freeman and Sweeney show that simply disseminating existing evidence will not lead to its implementation. Primary care organisations need to create learning environments that capitalise on the wealth of knowledge held within teams. Only with such a foundation will the dissemination of evidence based medicine be worth while.

Simon de Lusignan senior lecturer, primary care informatics

Sally Wells honorary research assistant, primary care informatics

swells@sghms.ac.uk

Andrew Singleton non-medical research scientis Department of General Practice and Primary Care, St George's Hospital Medical School, London SW17 0RE

1 Freeman AC, Sweeney K. Why general practitioners do not implement evidence: qualitative study. BMJ 2001;323: not implement evidence:

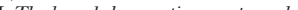
Japanese companies create the dynamics of innovation. New York: Oxford University Press, 1995.

3 Csordas T. Embodiment and experience. Cambridge: Cambridge University Press, 1994.

4 Wyatt JC. Clinical knowledge and practice in the information age: a handbook for health professionals. London: Royal Society of Medicine Press, 2001.

\section{Adult obesity and growth in childhood}

Fuel mediated teratogenesis driven by maternal obesity may be responsible for pandemic of obesity

EDITOR-Parsons et al highlight the importance of maternal weight on birth weight and future obesity in the offspring. ${ }^{1}$ They emphasise the importance of genetics and debate the relation between reduced intrauterine growth on future obesity but do not discuss the role of fuel mediated teratogenesis during fetal development. ${ }^{2}$

Fuel mediated teratogenesis proposes that intrauterine exposure of the fetus of women with diabetes in pregnancy to an excess of fuel (for example, glucose) causes permanent fetal change, leading to malformations, greater birth weight, and an increased risk of developing type 2 diabetes in later life. ${ }^{2}$ More recently, obesity in the off- 
spring has been included as an outcome of fuel mediated teratogenesis in pregnancies complicated by diabetes. ${ }^{3}$ However, maternal fuel supply across a population is a continuum, and the criteria for gestational diabetes may not be sufficient to differentiate between a diabetogenic and a nondiabetogenic intrauterine milieu.

We investigated the relation between first trimester body mass index and glycaemia at 36 weeks' gestation and birth weight and umbilical cord insulin concentrations in the pregnancies of 63 Polynesian women without gestational diabetes. ${ }^{5}$ We found that the greater the maternal body mass index (divided into thirds $(<25.0,25.0-31.7, \geqslant 31.8$ $\left.\mathrm{kg} / \mathrm{m}^{2}\right)$ ) the bigger the baby, the higher the maternal fasting glucose concentration (5.1 (SD 0.6), $5.0 \quad(0.5), \quad 5.3 \quad(0.5) \quad \mathrm{mmol} / \mathrm{l}$; $\mathrm{P}=0.097$ ), and the higher the geometric mean of the umbilical cord insulin concentration $(10.0,14.0,14.9 \mu \mathrm{mol} / \mathrm{l} ; \mathrm{P}=0.015)$. There were no differences across the thirds of body mass index in concentrations of cord leptin or insulin-like growth factor-I.

We hypothesised that increasing maternal obesity is associated with increasing maternal glycaemia, thereby stimulating fetal insulin secretion and raising the potential for obesity in the offspring. As plasma glucose is a continuous variable the relation between glycaemia and the future development of diabetes and obesity in the offspring that is found in diabetes in pregnancy ${ }^{3}$ is also likely to be present in those offspring at the upper end of the normal range. This is relevant for the debate over diagnostic criteria and management of gestational diabetes.

The public health implications of the hypothesis that fuel mediated teratogenesis may be driven by maternal obesity are enormous. If the hypothesis is confirmed attention should be directed towards controlling obesity and maximising fitness among women before pregnancy. More aggressive approaches to hyperglycaemia during pregnancy through a lowering of the criteria for gestational diabetes and more widespread use of insulin treatment in gestational diabetes may also need to be considered.

David Simmons foundation chair in rural health Department of Rural Health, University of Melbourne, PO Box 6500, Shepparton, Victoria 3630, Australia

dsimmons@unimelb.edu.au

Bernhard H Breier associate professor

Faculty of Medical and Health Sciences, University of Auckland, Private Bag 92019, Grafton, Auckland, New Zealand

Parsons TJ, Power C, Manor O. Fetal and early growth and body mass index from birth to early adulthood in 1958 British cohort: longitudinal study. BMJ 2001;323:1331-5. (8 December.)

2 Freinkel N. Of pregnancy and progeny. Diabetes 1980;29:1023-35.

3 Pettitt DJ, Bennett PH, Knowler WC, Baird HR, Aleck KA Gestational diabetes mellitus and impaired glucose tolerance during pregnancy: long term effects on obesity and glucose tolerance in the offspring. Diabetes 1985;34 (suppl 2):119-22.

4 Silverman BL, Metzger BE, Cho NH, Loeb CA. Impaired glucose tolerance in adolescent offspring of diabetic mothers. Diabetes Care 1995; 18:611-7.

5 Simmons D, Breier B. Do Polynesians have obesity driven fuel-mediated teratogenesis? Diabetes Care 2000;23: 1855-7.
Obstetricians seem reluctant to consider interventions to reduce mean birth weight

EDIToR-Law's editorial contains the suggestion that "interventions to prevent obesity in women of childbearing age give long term benefit to their children and to the women themselves." ${ }^{1}$ We have found that birth weight is positively correlated with maternal body mass index in early pregnancy and maternal fasting plasma glucose concentrations in the third trimester. ${ }^{23}$

We have shown a positive relation between maternal body mass index in early pregnancy and cord plasma insulin concentrations, which has since been confirmed by others. ${ }^{4}$ Fetal insulinisation is a marker of variation in birth weight, particularly in respect of the size of the newborn fat organ, as is well known from the example of maternal diabetes complicating pregnancy. The mechanism for this is that maternal fat mass is related to maternal insulin resistance, which determines the fasting and postabsorptive plasma glucose concentration.

Healthy non-diabetic pregnant women spend about 16 hours a day in the fasting or postabsorptive state, and glucose crosses the placenta by facilitated diffusion. Thus even the relatively modest graded changes in fasting and postabsorptive plasma glucose concentration that we observed (body mass index <26, $4.13 \mathrm{mmol} / \mathrm{l} ; 26-30,4.63$ $\mathrm{mmol} / \mathrm{l}$; and $>30,4.96 \mathrm{mmol} / \mathrm{l})$, in persisting for the whole of the second half of pregnancy, are responsible for a considerable excess provision of substrate to the fetuses of obese gravida. This increased transfer of glucose stimulates fetal insulin production.

We also studied postpartum body composition in relation to maternal body mass index in early pregnancy. We noted that the obese women, but not the normal weight or overweight women, failed to lose fat gained in pregnancy at the suprailiac skinfold six months after delivery. This was reflected in an increase in the waist:hip ratio, a marker for the risk of subsequent diabetes. ${ }^{5}$

We have suggested that randomised controlled trials of diet and supervised exercise targeted at obese women in the year after childbirth might result in longterm health benefits for the women and lower birth weights of any future children they might have. These suggestions have failed to interest any bodies that give research grants. This may be because obstetricians' obsession with avoiding low birth weight means that they are reluctant to consider any intervention that might reduce mean birth weight, however beneficial that might be.

Robert Fraser reader in obstetrics and gynaecology. Section of Reproductive and Developmental Medicine, University of Sheffield, Sheffield S10 2SF g.m.burkinshaw@sheffield.ac.uk

Hora Soltani research midwife

Derby City Hospital, Derby DE22 3NE

1 Law C. Adult obesity and growth in childhood. $B M$ J 2001;323:1320-1. (8 December.)

2 Soltani KH, Bruce C, Fraser RB. Observational study of maternal anthropometry and fetal insulin. Arch Dis Child 1999;81:F122-4.

3 Soltani H, Fraser RB. A longitudinal study of maternal anthropometric changes in normal weight, overweight and obese women during pregnancy and postpartum. Br J Nutr 2000;84:95-101.

4 Geary M, Hindmarch PC, Rodeck CH. Authors' reply. Leptin concentrations in maternal serum and cord blood: relationship to maternal anthropometry and fetal growth. BrJ Obstet Gynaecol 2000;107:831.

5 McKeighe PM, Pierpoint T, Ferrie JE, Marmot MG. Relationship of glucose intolerance and hyperinsulinaemia to body fat patterns in south Asians and Europeans. Diabetologia 1992;35:785-91.

\section{Association of birth weight with adult weight is confounded by maternal body mass index}

EDitor-Parsons et al showed that the association between birth weight and adult body mass index is largely explained by self reported maternal body weight. ${ }^{1}$ Although the authors said that this was the first report that maternal weight and other confounding variables may explain the association between birth weight and adult weight, we published similar conclusions after studying a North American cohort of African descent. $^{2}$

In the 354 subjects in our study we also investigated the influence of birth weight on adiposity in young adulthood and the impact of potential confounding factors on this association. The adulthood adiposity (expressed in standard deviations of triceps and subscapular skinfold thickness measured at age 20) increased with increasing fifths of birth weight, adjusted for gestational age, in the univariate analysis (test for trend: $\mathrm{z}=2.84$, $\mathrm{P}=0.004)$. After adjustment, with multiple regression, for pre-pregnancy maternal body mass index, birth order, and sex, however, this association disappeared $(\mathrm{P}=0.39)$.

We therefore concluded, as Parsons et al did, that in this North American cohort "an observed association of birth weight and adult weight might be confounded by other important factors in the absence of adjustment for these factors," ${ }^{2}$ in particular by maternal body mass index.

Nicolas Stettler assistant professor of paediatrics and epidemiology

nstettle@cceb.med.upenn.edu

Virginia A Stallings professor of paediatrics Division of Gastroenterology and Nutrition, Children's Hospital of Philadelphia, Philadelphia, PA 19104-4399, USA

1 Parsons TJ, Power C, Manor O. Fetal and early life growth and body mass index from birth to early adulthood in 1958 British cohort: longitudinal study. BMJ 2001;323:1331-5. (8 December.)

2 Stettler N, Tershakovec AM, Zemel BM, Leonard MB, Boston RC, Katz SH, et al. Early risk factors for increased adiposity: a cohort study of African American subjects followed from birth to young adulthood. Am J Clin Nutr 2000;72:378-83.

\section{Mothers tend to pass their dietary habits on to their children}

EDITOR-Parsons et al examined the relation between birth weight and body mass index at age 33 in a large, prospectively studied British cohort. ${ }^{1}$ Numerous potential confounders were examined, but the most important seemed to be that the prepregnancy body mass index of these children's mothers (but not their fathers) was the main determinant of adult obesity.

The authors conclude that their results do not support the theory that fetal growth 
has an effect on adult obesity. They describe their main finding as unsurprising but do not say why. The explanation is presumably a prosaic one: mothers (rather than fathers) are the parents who usually buy and prepare food and feed small children. Eating patterns and food preferences are established in early life and are difficult to change. Overweight mothers are likely to pass on to their children dietary habits that will predispose to adult obesity - a reminder, in this era of genetics, that there is more than one mode of inheritance.

Tim Cundy associate professor

Department of Medicine, University of Auckland,

Auckland 1001, New Zealand

t.cundy@auckland.ac.nz

1 Parsons TJ, Power C, Manor O. Fetal and early life growth and body mass index from birth to early adulthood in 1958 British cohort: longitudinal study. BMJ 2001;323:1331-5. (8 December.)

\section{Factors that programme resistance to} obesity must be identified

EDITOR-In her rapid response to Law's editorial Miller states that modern trends in food production and marketing and the exceptionally effective marketing of unhealthy food are strong contributors to obesity. ${ }^{2}$ Unfortunately, her argument misses another side of the story, also totally ignored by Law-namely, the plunging levels of physical activity among children and adults alike.

Clearly, diet alone does not explain the fact that more than half of British adults are overweight or obese. The public health message promoting low fat diets has been widely accepted since the early 1980s and is now almost universally known, and yet over the same time rates of obesity have more than doubled.

Children in the United Kingdom today are destined to become the fattest generation of adults yet seen. Fewer than 1 in 10 now walk to school, with most parents opting to use their car for the school run. In the school curriculum physical activity is less important than literacy and numeracy, as the government insists on high standards. In many primary schools children may take part in less than half an hour of organised exercise after time for changing is allowed. In leisure time children are predominantly sedentary, using computers and television for an average of five hours a day.

There is no strong evidence that obese children go on to become obese adults or to have an increased risk of later disease related to obesity. ${ }^{4}$ Clearly, though, establishing a sedentary habit in the developing years will increase the chances that the same patterns of behaviour will persist into adulthood. Given that most adults are now in non-manual, sedentary occupations, the low levels of energy expenditure associated with preferred leisure activities will surely lead to a further progression of the current epidemic of obesity.

Interest in the relation between early life events and later health is clearly important to public health. With regard to obesity, however, it is more imperative to study the lifestyle behaviours of families prone to obesity than to look for possible biological explanations. Attempts to establish associations between fetal life and long term body composition would be better directed at identifying factors that programme resistance to obesity and offer some hope for reversing current trends.

Simon Langley-Evans lecturer in human nutrition Division of Nutritional Biochemistry, University of Nottingham, School of Biosciences, Loughborough LE12 5RD

simon.langley-evans@nottingham.ac.uk

1 Miller L. A link between obesity and greed [electronic response to Adult obesity and growth in childhood]. bmj.com 2001 (bmj.com/coi/eletters/323/7325/1320 17978; accessed 1 March 2002).

Law $C$ Adult obesity and growth in childhood. $B M J$ 2001;323:1320-1. (8 December.)

Prentice AM Jebb SA Obesity in Britain: gluttony or sloth? BMJ 1995;311:437-9.

L, Ianont D, Craft AW. Tnplications of

Wright CM, Parker L, Lamont D, Craft AW. Implications of families cohort study. BMJ 2001;323:1280-4. (1 December)

\section{Implications of childhood obesity for adult health}

\section{Message on childhood obesity was missed}

EDITOR-We are concerned that Abbasi's website of the week review on the article by Wright et al may have left both health professionals and the public with the erroneous impression that obesity in (peripubescent) childhood does not predict obesity in later life and is not a cause for concern. ${ }^{12}$

The data of Wright et al show that body mass index in childhood and at age 50 is strongly associated-for example, among children in the top quarter of weight at 9 years, $73 \%$ (59/81) become overweight or obese adults at age 50 , whereas of those who are in the top quarter at $13,82 \%(64 / 78)$ are overweight or obese at age 50. This is a highly significant association, and it is not true that thin children are just as likely to be fat adults. It is also important to remember that the childhood of this sample fell into a postwar environment where undernutrition and other stressors led to impaired growth, and adult obesity was not a public health issue. The environment has changed radically, to the extent that the prevalence of adult obesity in England has trebled in the past two decades, and so any associations in Wright et al's sample are all the more surprising. ${ }^{3}$

The prevalence of obesity in children is increasing, and it carries its own health risks irrespective of later adult morbidity. ${ }^{4}$ Would health professionals in 40 years' time thank us for ignoring the public health implications of childhood obesity now? We think not.

E Leigh Gibson senior research fellow l.gibson@ucl.ac.uk

Jane Wardle professor of clinical psychology Carolyn Edwards clinical psychologist Lucy Cooke research fellow

ICRF Health Behaviour Unit, Department of Epidemiology and Public Health, University College London, London WC1E 6BT

1 Wright CM, Parker L, Lamont D, Craft AW. Implications of childhood obesity for adult health: findinos from thousan families cohort study BMJ 2001:323:1280-4 (1 Decousan

(anbasi K. Childhood obesity. BMJ 2001,323:1314.

Abbasi K. Childhood obesity. BMJ 2001;323:1314. (1 December.)
3 National Audit Office Report. Tackling obesity in England. London: Stationery Office, 2001. (NAO 2001; report HC220.)

4 Chinn S, Rona RR. Prevalence and trends in overweight and obesity in three cross sectional studies of British children, 1974-94. BMJ 2001;322:24-6.

5 Must A, Strauss RS. Risks and consequences of childhood and adolescent obesity. Int J Obes 1999;23(suppl 2):S2-11.

\section{Authors' reply}

EDITOR-We agree with Gibson et al that childhood body mass index tracks strongly with adult body mass index, a point we made clearly in our paper. However, our important and new observation was that childhood body mass index is a poor predictor of adult percentage body fat, suggesting that it is mainly build that tracks throughout life and not adiposity. Although we cannot be sure that body mass index in childhood was appropriately classified in all of the children in our study, the substantial differences between the results with body mass index and percentage body fat need to be understood.

Frank obesity during childhood was uncommon in our study, and we therefore could not analyse the fate of very obese children and did not purport to do so. Other studies suggest that they may indeed do badly. We were able to study whether plump (rather than obese) children should excite concern, and whether comparative thinness as a child offers protection either against obesity or risk of cardiovascular disease in adult life. We found consistent evidence that neither was true.

As we argued, our results were consistent with published studies. This research tends to be selectively quoted, apparently to support the paradigm that obesity has its origins in childhood, with the implication that by adulthood it is too late to do anything about it. For example, many studies, including ours, show that most obese adults were not fat children, but this is not generally known and is rarely mentioned when childhood obesity is discussed. Similarly, we found two previous studies similar to ours examining adult health consequences of childhood overweight. ${ }^{2}$ The study that suggested a bad outcome is widely cited, ${ }^{1}$ while the other much larger study, which was consistent with ours, was only recently rediscovered by one diligent reviewer and is seldom otherwise cited.

We found no evidence that being a thin child is of long term health benefit. We thus argue that efforts to turn the tide of adult obesity will be misdirected it they are directed primarily at turning plump children into thin children. The target should be those who are truly at risk: inactive, overeating adults.

Charlotte M Wright senior lecturer

University of Glasgow, Glasgow G3 8SJ charlotte.wright@clinmed.gla.ac.uk

Louise Parker reader in epidemiology

Sir James Spence Institute of Child Health,

University of Newcastle upon Tyne, Royal Victoria Infirmary, Newcastle NE1 4LP

Vanhala M, Vanhal P, Kumpusalo E, Halonen P, Takala J. Relation between obesity from childhood to adulthood and the metabolic syndrome: population based study. BMI 1998;317:319

2 Abraham S, Collins G, Nordsieck M. Relationship of child-

hood weight status to morbidity in adults. HSMHA Health Report 1971;86:273-84. 


\section{Combining high quality clinical and interpersonal care}

EDITOR-We are five general practitioners sharing the same premises, practice nurses, receptionists, and practice manager, and we read with interest the paper on high quality care in general practice by Campbell et al. ${ }^{1}$ They found that smaller practices scored more highly for access but that diabetes care was inferior to that of larger practices, and they say that there may be a trade off between high quality clinical care and interpersonal care.

We believe that these elements are not mutually exclusive and that the advantages of personal care associated with smaller practices may be combined with the higher quality clinical care of larger practices if small practices adopt a model of health care delivery similar to our own. The corollary is that large practices should operate a system of personal lists. Teamwork is increasingly important for high standards of care, and small practices can achieve this by combining resources.

A M Siddiqui general practitioner

J Lewis general practitioner

A S Dongre general practitioner

S Martin general practitioner

M Doublet-Stewart general practitioner

morris.doublet-stewart@gp-p92606.nhs.uk

Grasmere Street Health Centre, Leigh, Lancashire WN7 1XB

1 Campbell SM, Hann M, Hacker J, Burns C, Oliver D, Thapar A, et al. Identifying predictors of high quality care in English general practice: observational study. $B M J$ 2001;323:784. (6 October.)

\section{Social deprivation affects outcome of nocturnal enuresis}

EDITOR-Evans has written on evidence based management of nocturnal enuresis. ${ }^{1}$ This article, together with the guidelines of the Enuresis Resource and Information Centre (ERIC) on minimum standards of practice in the treatment of enuresis, ${ }^{2}$ should be used to provide a framework within which enuresis services can be audited and evaluated.

We recently completed the first cycle of an audit to evaluate the enuresis service in two of our clinics, run by the same team (a doctor and nurse). Clinic A caters for children from a higher socioeconomic background living in the more affluent villages, and clinic B caters for children from an area with a lower socioeconomic background. We looked through the files of 56 children treated for enuresis over one year (Jan-Dec 1999) in the clinics and evaluated the service provision, including the success rates of the interventions (reward charts, enuresis alarms, and drug treatment) as well as dropout rates.

The success rate for reward charts was $54 \%(7 / 13)$ for clinic A $v 26 \%(8 / 31)$ for clinic $\mathrm{B}$, while the success rate for the use of alarms was $100 \%(3 / 3) v 17 \%(1 / 6)$. Alarms in clinic B were not used by the family for a sufficient time for them to be effective as they were returned within a few days of being issued. Drop outs (those failing to attend two consecutive appointments without giving any reason) were higher in the more deprived area $(23 \%(3 / 13)$ for clinic A $v 45 \%(14 / 31)$ for clinic B).

Our results suggest that social deprivation has a negative bearing on the management of nocturnal enuresis. We need to develop more supportive services for parents in our enuresis clinic in the more deprived area to improve their cooperation and motivation, thereby improving the outcome.

Daisy Rolands staff grade community paediatrician dnrolands@aol.com

Eleni Stathopulu consultant community paediatrician Dartford, Gravesend, and Swanley Primary Care NHS Trust, Livingstone Hospital, Dartford DA1 1SA

1 Evans JHC. Evidence based paediatrics: Evidence based management of nocturnal enuresis. BMJ 200 1;323:1167-9. (17 November.)

Hunt S. The concept of outcome. Scand J Urol Nephrol 1997;suppl 183:71-4.

\section{Breast screening seems driven by belief rather than evidence}

EDITOR-The aim of the NHS breast screening programme when it was set up in 1988 was to reduce mortality from breast cancer by $25 \%$ by the year 2000 . In her foreword to the latest report of the programme, for the year 2000, Yvette Cooper, undersecretary of state, states: "Breast cancer mortality in England and Wales decreased by $21.3 \%$ between 1990 to 1998 , and it is estimated that $30 \%$ of this reduction was due to breast screening." But $30 \%$ of $21.3 \%$ equals $6.4 \%$.

Evidence published in 2001 indicates that "there is no reliable evidence that screening for breast cancer reduces mortality"' It also states: "breast cancer mortality is a misleading outcome measure." Why then, in the long awaited revised leaflet in the information campaign, are various figures of up to a 40-50\% reduction in mortality (from the Swedish two counties trials) used instead of the findings from this systematic review, undertaken according to the most rigorous protocol for the Cochrane Library? Horton, in his commentary on the review, pleads for carefu reflection and discussion because "the implications for women and for policymakers are substantial."3 Is anyone listening?

The coincidence of publication of these long awaited leaflets with publication of the overview has made apparent the scientific community's subjectivity. ${ }^{4}$ It has also highlighted the community's inability to engage in proper debate about these findings rather than in the public, unscientific, and potentially destructive instant refutations and condemnations it has engaged in so far.

For those who launched the information campaign to say that the revised leaflets "heralded a new relationship of trust and honesty between patients and the NHS" is overoptimistic in the extreme. The leaflet does not provide women with even the most basic details about the benefits, risks, limitations, and consequences, or alternatives, of mammographic screening. The social and financial, as well as the physical, consequences can be considerable and unexpected and should be described, as the General Medical Council recommends.

Healthy women should be provided with this information so that they are enabled to make their own personal trade offs according to their individual circumstances, health profile, and preferences, not fobbed off with the benefits of "catching it early" but none of the most up to date evidence. Three "levels" of leaflet are to be provided for men considering prostate specific antigen testing for prostate cancer. Why can't women have this facility?

Hazel Thornton independent advocate for quality in research and healthcare

Saionara, Rowhedge, Colchester CO5 7EA

hazelcagct@aol.com

1 Department of Health. NHS cancer screening report. Reducin the risk:breast screening programme. London: $\mathrm{DoH}, 2000$. 2 Olsen O, Goetzsche PC. Cochrane review on screening for breast cancer with mammography. Lancet 2001;358: 1340-2.

3 Horton R. Screening mammography - an overview revisited. Lancet 2001;358:1284-5.

4 Mayor S. Row over breast cancer screening shows that scientists bring "some subjectivity to their work." $B M J$ 2001;323:956. (27 October.)

5 General Medical Council. Seeking patients'consent: the ethical considerations. London: GMC, 1998.

\section{Price of interferon beta is similar in UK and Australia}

EDITOR-I was moved by Dyson's account of coming to terms with his wife's diagnosis of multiple sclerosis and the difficulties of obtaining access under the NHS to one of the three beta interferon products licensed for this indication. ${ }^{1}$ Only $2 \%$ of people with multiple sclerosis in the United Kingdom are receiving interferon beta, compared with $12-15 \%$ elsewhere in Europe and an even higher proportion in the United States. As I work for a company that manufactures an interferon beta product, albeit different to the one that was the subject of Dyson's personal view, I would like to provide some reasons why drug prices may differ between countries.

When our interferon beta (Betaferon, interferon beta-1b) was launched in the United Kingdom and Europe in 1995, worldwide prices were comparable. Huge currency differences have developed subsequently across Europe, with the pound being strengthened by a third to the Deutschmark since 1995.

Prices of branded pharmaceuticals to the NHS are controlled by the government. Schering Health Care Limited complies with the pharmaceutical pricing regulation scheme, negotiated between the Department of Health and the Association of British Pharmaceutical Industries. The scheme does not guarantee that the manufacturer makes any profit on a particular product. This differs from other European countries, 
where reimbursement can vary between categories of treatments. In Germany interferon beta is fully reimbursed through government insurance schemes; in Italy the price depends on the number of units sold.

The pharmaceutical industry also funds additional services in the United Kingdom as a result of underresourcing in our health system: we have fewer than one fifth the neurologists per head of population than in most other developed countries. ${ }^{2}$ For example, specialist nurses for patients with multiple sclerosis, supported wholly or partly by industry, make a huge contribution to the care of people with the illness, including the vast majority who do not receive any interferon beta or other disease modifying treatment.

As part of our compliance with the pharmaceutical pricing regulation scheme, the NHS price of Betaferon had two modulations last year, and in August was $£ 7263.97$ per patient per year. This is not so different to the price Dyson is paying for interferon beta from Australia.

Jacqueline C Napier associate medical director Schering Health Care, Burgess Hill, West Sussex RH15 9NE

jnapier@schering.co.uk

1 Dyson A. The price isn't right. BMJ 2001;323:407. (18 August.)

2 Kmietowicz Z. United Kingdom needs to double the number of neurologists. BMJ 200 1;322:1508.

\section{Data on take home naloxone are unclear but not condemnatory}

EDITOR-In Chicago we have been teaching active opiate injectors how to manage overdoses for some time, providing naloxone to appropriate people, as has been discussed in these letters columns. ${ }^{1}$ This programme now uses two physician volunteers who fill in the legally required prescription.

To date, we have reached over 550 people with this intervention and have received reports of 52 uses of naloxone in physically unresponsive and usually cyanotic peers. All the uses were successful, but people were disturbed by the experience. They may have been intellectually pleased that their peer was alive and that they had helped in such a way, but both the person who had taken the overdose and the person who had given naloxone were in no hurry to repeat the incident. Expecting the availability of naloxone to minimise someone's inhibitions about using it ignores the fact that using naloxone is unpleasant for all. An intramuscular dose of $1 \mathrm{ml}$ greatly reduces aftereffects and, in our programme, did not produce an opiate use response thanks to peer support during the interval from naloxone use to its wearing off.

Also, the availability of naloxone is something most people writing to the $B M J$ would probably not think about twice if it were for their own protection. How could such a clear personal protection be distorted into such maltreatment of others?

The science of the practice is limited, and there are few well-designed studies on this work. This is a result of not just its novelty but also the resistance of funding bodies and many researchers to study this controversial practice. Funding of good research on and practice in using a strategy based on common sense such as take home naloxone is in short supply. Our programme receives no external funding, but it needs such attention to grow and develop. Being opposed to a potentially life saving practice in the absence of data proving it wrong is a dangerous proposition. Unclear data should lead to unclear conclusions, not condemnation.

Dan Bigg director

Chicago Recovery Alliance, PO Box 368069 Chicago, IL 60636, USA cra@attglobal.net

1 Graham CA, McNaughton GW, Ireland A, Cassells K, Mountain D, Blackwood G, et al. Take home naloxone for opiate addicts. BMJ 2001;323:934. (20 October.)

\section{Venous ulcers may be associated with gravitational eczema}

EDITOR-Chan et al report on several patients treated with four layer compression bandaging for venous ulceration who went on to develop toe and cleft ulceration. ${ }^{1}$ In south Lincolnshire, patients with venous ulcers have been treated with such bandaging in the community by district nurses since the late 1990s. Before then only selected patients were given this treatment in hospital because it was not prescribable on the NHS. It is now. We therefore seldom see these patients in hospital now except when they are referred with problems-for example, non-healing ulcers or gravitational eczema (dermatitis).

Some patients with gravitational eczema may present, in addition, with superficial ulcerations (erosions) that mimic venous ulcers. The important signs for the diagnosis of eczema in these superficial ulcers are exudation (weeping, oozing) and crusting. The ulcers heal rapidly with potent topical steroids. The explanation for the development of these ulcers is that eczema starts with tiny fragile papules and vesicles, which break down easily and coalesce to form superficial exudative ulcers (erosions). The crusting is due to the drying up of the exudate.

This is well illustrated in the photograph in Chan et al's paper, which showed much crusting of the dorsum of the feet and toes. Patients with venous ulcers may also show signs of other venous disease-for example, gravitational eczema, which may extend to the feet and toes; oedema; hyperpigmentation; and lipodermatosclerosis. Chan et al's patient may have had gravitational eczema.

Chan et al say that the ulcers improved with foot elevation but recurred within two weeks. Potent topical steroid should be tried in such cases: if there is an element of eczema one expects healing in about two weeks.

C M Quartey-Papafio locum consultant Department of Dermatology, United Lincolnshire Hospitals, Pilgrim Hospital, Boston PE21 9QS Anne.Cook@ulh.nhs.uk

1 Chan CLH, Meyer FJ, Hay RJ, Burnard KG. Toe ulceration associated with compression bandaging: observational study. BMJ 2001;323:1099. (10 November.)

\section{Violence may be serious in men with body dysmorphic disorder}

EDitor-Phillip and Castle in their editorial on body dysmorphic disorder in men said that patients disappointed with ineffective surgical or dermatological treatment may become violent towards the treating physician. ${ }^{1}$ There are grounds for considering that violence may be a more serious problem in this disorder than hitherto recognised, especially in view of the associated use of anabolic steroids.

I have reported the case of a patient with body dysmorphic disorder whose violence against others led to his compulsory detention in a secure unit under the Mental Health Act. ${ }^{2}$ My review of the literature on body dysmorphic disorder suggested violence to be more common in the condition than previously recognised.

Perugi et al found that $29 \%$ of 34 men and $46 \%$ of 24 women with body dysmorphic disorder responded affirmatively to at least one of the following questions: "Are you ever so enraged and in despair that you lose control and become insulting, aggressive or violent towards your relatives and friends?" and "At these times do you break any object or punch and kick walls and doors?" Similarly, $38 \%$ of the young patients in Albertini and Phillips' study acknowledged a history of violence owing to body dysmorphic disorder.

These two studies differ from others in that the subjects were asked directly about aggressive and violent behaviour. Their answers revealed an unexpectedly high incidence. Phillips and Castle indicate that men and boys do not volunteer their core symptoms of body dysmorphic disorder. Unless sought by direct questioning, this is also likely to apply to associated violence and aggression, which may profoundly affect the life of the person with body dysmorphic disorder and his family.

Philip Lucas consultant forensic psychiatrist North London Forensic Service, Hadley Lodge, Chase Farm Hospital, Enfield EN2 8JL

philip.lucas@enfieldcc-tr.nthames.nhs.uk

1 Phillips KA, Castle DJ. Body dysmorphic disorder in men BMJ 201;323:1015-6. (3 November.)

2 Lucas P. Body dysmorphic disorder and violence: case report and literature review. J Forensic Psychiatry (in press). 3 Perugi G, Akiskal H, Giannotti D, Frare F, Di Vaio S, Cassano G. Gender-related differences in body dysmorphic disorder (dysmorphophobia). I Neru Ment Dis 1997; 185:578-89.

4 Albertini RS, Phillips KA. Thirty-three cases of body Acad Child Adolesc Psychiatry 1999:38:453-9. 


\section{Chinese medicines for slimming still cause health problems}

EDITOR-Local events caused great public health concern recently. After the referral of a 44 year woman with new onset hypertension, palpitation, anxiety, and a body mass index of $19 \mathrm{~kg} / \mathrm{m}^{2}$ it became apparent that an alarming number of the local population had been attending a particular Chinese herbalist for weight loss remedies. Most had been taking multiple preparations-as many as nine-and described "spectacular" results. Several reported considerable cardiovascular symptoms but were reassured that Chinese medicines are natural and can cause no harm. We analysed the prescribed substances and the urine of several patients.

Use of aristolochia extract in Chinese medicines for weight loss has been implicated in renal failure and urogenital malignancy $^{12}$ and is now banned. Our patients had no evidence of renal complications. We initially suspected that the preparations might contain an ephedra alkaloid (Ma Huang in Chinese medicine); the dangers and widespread use of dietary supplements containing ephedra have been highlighted. $^{3}$

Analysis by gas chromatography, however, showed a high concentration of fenfluramine in two of the products (sold as Qian $\mathrm{Er}$ and Ma zin dol) and also in the patients' urine. Subsequently a student nurse was admitted to this hospital with severe fenfluramine toxicity, which developed two hours after her first dose of a herbal slimming remedy.

After reports of an association with pulmonary hypertension ${ }^{4}$ fenfluramine was withdrawn even as a prescription only medicine in 1997. Its use as described is obviously illegal. Further toxicological analysis of the multiple products prescribed is ongoing: given the practice of polypharmacy, the potential for drug interaction is self evident.

This case is now under investigation by the Medicines Control Agency, which has yet to establish exactly where in the chain of supply adulteration with fenfluramine occurred. The agency recently published a report on traditional ethnic medicines and present medicines law. ${ }^{5}$

The vast majority of Chinese herbalists and practitioners of other traditional medicines are responsible, professional, and caring. Our recent experience, however, highlights how the public's trend to believe, often with great naivety, in natural remedies

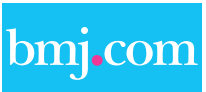

\section{Rapid responses}

Correspondence submitted electronically is available on our website can be abused. Stringent regulation of traditional medicines, at least to the standards of conventional practice, is

Karl Metcalfe consultant physician

Cathryn Corns consultant biochemist Michael Fahie-Wilson consultant biochemist Paul Mackenzie chief biomedical scientist Southend Hospital, Westcliff-on-Sea, Essex SS0 0RY

1 Vanhaelen M, Vanhaelen-Fastre R, But P, Vanherweghem J-L. Identification of aristocholic acid in Chinese herbs. J-L. Identification of

Lancet 1994;343:174.
Nortier JL, Martinez MC, Schmeiser HH, Arlt VM, Bieler 2 Nortier JL, Martinez MC, Schmeiser HH, Arlt VM, Bieler
CA, Petein M, et al. Urothelial carcinoma associated with the use of a Chinese herb (Aristolochia fangchi). $N$ Engl Med 2000;342:1686-92.

3 Haller CA, Benowitz NL. Adverse cardiovascular and central nervous system events associated with dietary supplements containing ephedra alkaloids. $N$ Engl I Med 2000;343:1833-8

4 Brenot F, Harve P, Petitpretz P, Parent F, Duroux P, Simonneau G. Primary pulmonary hypertension and fenfluramine use. Br Heart J 1993;70:537-41. Medicines Control Agency. Traditional ethnic medicines:public health and compliance with medicines law. London: MCA 2001

EDITOR-The pharmaceutical industry seems to be dominated by packaging initiatives that unnecessarily compromise patient compliance and thus safety. A middle aged male patient in Ireland reports the challenge he faces daily as a result of inventiveness in product presentation. Currently he is prescribed six not unusual medications for a hypertensive condition and related effects, one replacing a previous drug. The packaging of each is in blister packs, one tablet to be taken per day, but the total nonstandardisation of presentation is shown in the table.

The utter confusion is clear: no two packages are the same. Whether a blister pack covers one week or two, presentation may be in parallel rows or round the pack. Each pack has to be considered separately, the end of the run of removed tablets identified, and the next to be used identified.

The only commonality is that the labelling of days of the week takes the form urgently needed. karl.metcalfe@southend.nhs.uk

\section{Pharmaceutical packaging can induce confusion}

of three letters (with "THURS" for Thursday in six cases). The print is always in fine lettering and never larger than 12 point. It is in capitals in six cases, and seldom in a dark colour. The typeface of one pack is such that if "MON" is viewed upside down, it reads as an imperative "NOW."

Three products originate or are packed in Ireland, three in England, and one is labelled as "UK-Ireland" packaging of a French licensed product. The only correlation is that it is the English products that give Sunday and Monday equal position as the start of the week.

This patient is fit, mentally competent, and has good vision, yet this variety faced at breakfast time and bedtime needs alertness - at a time of day when this may be compromised. As pattern of removal is more prominent than indistinct printing, but leads to false decisions given the different patterns of presentation, wrong dosage is very possible and does occur. These drugs are more likely to be prescribed in the later part of life-for elderly or confused patients the risks are obvious, yet unnecessary.

There seems no need for this variety. Pharmaceutical manufacturers are not competing for patients on the basis of consumer choice of packaging, and patients have this non-conformity forced on them. Patients are unnecessarily put at risk by design inventiveness.

Producers of other products based on days of the week, such as diaries, calendars, and television listings, have moved towards a high degree of concordance even though consumers have personal choice. But in pharmaceuticals, where health and life are involved, this is not the case.

In the interests of consumer safety and optimised compliance this is an issue that would benefit from standardisation, including also a specification of bold or heavy type. Given the international nature of pharmaceutical supply, it seems a legitimate subject for a European approach.

Michael Rigby senior lecturer

Centre for Health Planning and Management, Keele University, Keele, Staffordshire ST5 5BG m.j.rigby@keele.ac.uk

Packaging of seven commonly prescribed drugs for one patient

\begin{tabular}{|c|c|c|c|c|c|}
\hline Product No & $\begin{array}{l}\text { No of weeks } \\
\text { per pack }\end{array}$ & Format of week & $\begin{array}{l}\text { Day starting } \\
\text { week }\end{array}$ & Location of print & Colour of print \\
\hline 1 & 2 & $\begin{array}{l}\text { Up one side, down the } \\
\text { other, clockwise }\end{array}$ & Sun/Mon & Foil side & Turquoise \\
\hline 2 & 1 & $\begin{array}{l}\text { Parallel rows of } 4 \text { and } \\
3 \text { days }\end{array}$ & Mon & Foil side & Maroon \\
\hline 3 & 2 & $\begin{array}{l}\text { Heart shaped circle per } \\
\text { week, clockwise }\end{array}$ & Sun/Mon & Foil side & $\begin{array}{l}\text { White on red (red on } \\
\text { white for } 2 \text { days a week) }\end{array}$ \\
\hline 4 & 4 & Parallel rows & Mon & Both sides† & $\begin{array}{l}\text { Blue, striated silver } \\
\text { background }\end{array}$ \\
\hline 5 & 2 & Parallel rows & Mon & Blister side & Red \\
\hline $6^{*}$ & 1 & $\begin{array}{l}\text { Up one side, down the } \\
\text { other, clockwise }\end{array}$ & Sun/Mon & Foil side & Black \\
\hline 7 & 2 & Parallel rows & Mon & Foil side & Reversed grey on foil \\
\hline
\end{tabular}

*Replaced 7.

But one line is in fine print between middle two, manufacturer's name being more prominent. 